\title{
Discussion on the Education Mode of Art Design in the View of Cultural and Creative Industry
}

\author{
Hong Li \\ Department of Art, Science and Technology College Gannan Normal University, Ganzhou 341000, China \\ lihonggn@126.com
}

Keywords: cultural and creative industry; art design; workshop; industry; education and research

\begin{abstract}
The 12th Five-year Plan of our country puts forward clearly that promote cultural industry to become pillar industry of national economy. For the flourishing development of cultural and creative industry, talent is the key factor. Because the "art design education lagging behind the modern manufacturing practice" in our country, it is particularly urgent for colleges and universities in our country to learn from the advanced experience of cultivating creative talents in western countries. Based on the advanced experience of art design education in overseas famous art colleges and universities, this paper explores the art design education in the models of international famous colleges and universities.
\end{abstract}

\section{Introduction}

Under the background of globalization, cultural and creative industries are a well-deserved sunrise industry. According to statistics, the growth rate of the benefit of cultural industry in China in recent years is more than $17 \%$, higher than the GDP growth rate. (1) The creative industry has become the most active in the world economy according to the global $<2010$ creative economy report. The economic sector of the force has the potential to create income, expand employment and increase export earnings. It also promotes social inclusion, cultural diversity and the development of human society. It is a new development option for developing countries. (2) China's "12th Five-Year" development plan explicitly proposed that the promotion of cultural industry become a new one. In fact, with scientific and technological progress and social development, it is an inevitable choice for China's economic development strategy to change the traditional way of economic growth and accelerate the upgrading from "made in China" to "China". The most fundamental and core element of the cultural and creative industry is the creative talents. In sharp contrast, the number and quality of our cultural and creative talents are in a serious gap. "Art design education in China is lagging behind the practice of modern manufacturing." on this premise, the innovation model of art design education in Colleges and universities is discussed, and the creative talents of developed countries are used for reference. It has become an urgent task for the training of creative talents in Colleges and universities to cultivate creative talents as soon as possible, which is of great significance for speeding up the development of cultural and creative industries in our country.

\section{The Present Situation of Art Design Education in Colleges and Universities in China}

In the 21st century, with the rapid development of China's cultural and creative industries, the demand for art and design personnel is increasing. China has become the largest country in higher art and design education in the world. According to preliminary statistics: at present, there are thousands of colleges and universities that have set up design major in China, and hundreds of thousands of students recruit students each year. Design specialty has become one of the hottest specialties in the development of Chinese colleges and universities. However, there are still a series of problems behind the scale. For a long time, the field of art and design education has been aware that "art and design education in our country lags behind the practice of modern manufacturing 
industry." Some scholars have pointed out that the design education in China is still in the early stage of development, and the creative talents in our country have not really finalized and matured. In addition, compared with foreign design colleges, most of them can offer various training courses to meet the needs of cultural and creative industry workers, thus driving the virtuous circle of the whole industry. There are few professional training, short-term training and distance education classes for cultural and creative industry workers in design colleges in our country. However, there is a phenomenon that the quality of employees is not high in the current cultural and creative industries in China, and the role of teaching and training needs to be further brought into play in colleges and universities. Third, design practice and market disconnect. Although our country is big some colleges and universities have set up art design major, but some design talents trained by colleges and universities are still criticized by enterprises as poor practical ability, which is out of line with the market. On the one hand, some teachers enter colleges and universities as soon as they graduate enter and lack practical experience; on the other hand, the traditional teaching management mode rarely creates practical opportunities for teachers and students. After entering the creative industry, there is bound to be the problem of disconnection with the standard of creative talents. At present, the research theory of creativity in colleges and universities and research institutions in China is still in the At the stage of introduction, the personnel engaged in creative research are relatively short, and there is still less platform for creative research, especially for the overall development strategy. The theoretical basis for the development of foreign creative industries, the formulation of policies, and the layout of industries are not enough. The research on talent strategy is limited to a brief introduction.

\section{Three Models of International Art and Design Education}

In contrast to the late start of art and design education in colleges and universities in our country, the art design education in Europe and America started early, and schools in different regions gradually formed their own characteristics in the long-term development, combined with regional characteristics. In the process of running a school, colleges and universities not only pursue individualized running school, but also pay attention to the cultivation of talents needed for the development of local cultural and creative industries. For a long time, the art design colleges in Europe and America have used the following three modes in teaching.

For junior students, art design schools in Europe and the United States usually arrange for students to study in wide-platform courses regardless of major. Upon completion of the platform course, the students will enter their respective professional fields of study. When the students master a certain degree of professional knowledge, they will enter into the regardless of professional, comprehensive interdisciplinary project learning. Taking the design major of Carnegie Mellon University College of Art as an example, general education based on basic platform carried out in the first year of university. It emphasizes the students' mastery of 2D and 3D skills, as well as their grasp of design ideas and design process. In the second and third years, students enter major studies, but in the In the fourth year, students study for cross-disciplinary projects regardless of major. In addition, to provide all students with a wide range of professional courses is also a major feature of European and American art and design schools. Take the London University of the Arts as an example. As the largest professional school in art in Europe, the London University of Art consists of six faculties. Each of the six colleges has its own specialties, with a clear breakdown of specialties, and the largest colleges offer as many as 30 specialties. The London University of the Arts has a rich curriculum that can found for undergraduates, graduate students and those already working.

\section{Workshop Model}

In addition to the traditional classroom, the workshop model is widely used in European and American art design schools. Workshops, which refer to a participatory, experiential, interactive learning model, usually consisting of 1020 members formed into a small group, with an experienced 
moderator in a particular field as the core, and members under their direction and through activities. Discussion, short talk and other ways to discuss a topic together the organizational model .2 this teaching model originated in Germany Bauhaus College. Gael Pius, founder of the institute and one of the founders of modern architectural design, advocates "equal emphasis on technology and art." the learning process is like the "factory apprenticeship", the identity of the student is "apprentice." In the course of teaching, teachers who serve as art form courses called "form tutors", who teach their theoretical courses and lead their professional development, while teachers who are technical and artisan ship courses are called "studio masters". As the practice, links require specific venues, the students' daily practice spaces-- workshops have gradually become the core of the practice links, and the practical model also known as, "workshop teaching".

Has the advantage of, through the workshop form, students' ability to "solve problems" and design innovation the ability of meaning, self-expression, and research can trained and improved in specific projects. The workshop is a bridge between theoretical knowledge and practical operation. Taking the Dormers Institute of Design in Italy as an example, various workshops have extensively integrated into the teaching process, and the core knowledge system of the subject has applied in practice. Students are free to form groups according to the project, and students from different academic backgrounds can brainstorm in the same team, both to facilitate cross-industry communication between students, but also to create different sparks. Schools for each workshop appoint a mentor who can be a well-known designer from a business or a school professor. The students finish their homework under the guidance of the tutor, who provides advice and advice, but does not participate in the making. In such workshops, students' initiative for self-learning maximized. At the same time, some workplace skills, such as expressive skills, team communication skills have also trained.

\section{Industry, University and Research Model}

Industry, school, scientific research and so on cooperate with each other, develop their own advantages, form a powerful advanced system of research, development and production integration, and embody the comprehensive advantage in the process of operation. Industry-university-research cooperation refers to the cooperation between enterprises and institutions of higher learning and scientific research institutes, usually referring to the cooperation between enterprises as the technological demand side and scientific research institutes or institutions of higher learning as the technological suppliers; its essence is to promote the effective combination of various factors of production needed to promote technological innovation.

\section{The Inspiration and Reference of International Art Design Education Model to our country and our University}

Since 2009, Tong ji University has made new plans and adjustments to its art and design disciplines and related resources, including the establishment of the Institute of Design and creativity and the establishment of the Sino-Italian Design and Innovation Center. To further, integrate the various resources in and outside the school, to serve the development of the subject of art and design.

Establishment of the Design and Creative Academy with the characteristics of "Open Innovation" in order to "meet the needs of the process of making in China and changing into Chinese creation"

\section{Construction of China-Italy Design Innovation Center Characterized by "Multi-functional platform"}

Relying on the disciplinary background of the strong engineering science of Tong ji University and the foundation of mutual cooperation with Italy, in 2010 10, according to the agreement between China and Italian government, the Ministry of science and technology of China set up the 
"center of design and innovation of Zhong yi" at Tong ji University. According to the plan, the center of design and innovation of China and Italy is a design education, research and development incubator, international exchange, activity exhibition and so on. The building of the platform will further promote the interrelated interaction between design related majors in Tong ji University and provide a platform for students to develop their talents.

Specifically, the China-Italy Design Innovation Center is committed to building the country with the task of promoting the cultivation of future cultural design talents.

Class I wish to design education platform. The platform designed to face the national, multi-form, multi-level international school-running projects;

To launch the China-Italy Design Education Master Program; to cooperate with the Italian Ministry of the Environment to open the Sino-Italian Green Energy-Saving Building Chair; to set up the China-Italy Design Education Scholarship for teachers and students; and to promote mutual understanding of design education between China and Italy. In the aspect of industry, education and research, China-Italy Design and Innovation Center will build a high-end platform for cooperation between Chinese and Italian enterprises, and create a national base for cross-industry cooperation of design innovation between China and Italy. According to the plan, the China-Italy Design Innovation Center will attract more than 50 famous design companies from both countries, such as architecture, urban design, industrial design, digital media, animation, vehicle design, etc. In order to form China's largest "China-Italy design innovation industry" cluster. By attracting enterprises that put design innovation in a strategic position, such as construction, fashion, automobile, electronics and Japan

In fostering small and medium-sized enterprises, China-Italy Design Innovation Center can play a role in promoting the transformation of Sino-Italian design research and development results. At the same time, the center will also encourage the creation of innovation driven by design, and build a platform for the combination of design creativity and industry. In addition, in order to promote "design research and technological innovation", the Center will organize "Industrial Design", "Cultural Heritage Conservation Design", "Fashion Design", "Urban Design"

From a larger perspective, Sino-Italy Design Innovation Center is located in Shanghai International Design Center. Its superior geographical location allows the Centre to promote the administration and production of the region through its operation,

In the process of integration of campus, park and community, we will promote the construction of Italian creative economy and Design Street. Through cooperation with Italian local government , we will promote " Chinese - Italian design cooperation " at the level of urban construction , creative economy and industry , and form a long - term cooperative exchange mechanism between the two countries ' design education, research, practice institutions and trade associations .

\section{References}

[1] Jin y p: rise of the High end: the multiple Tests of Cultural creativity, people's Forum, No. 3, 2011.

[2] Fan Yu gang, "Cultural creativity" drives the Future of China, people's Forum, No. 13, 2011.

[3] Gerhardt Mathias. "Chinese Design Education 1990-2005." Art Journal, May 20, 2006.

[4] Long An m: the cultivation and Development of Creative talents, Chinese Talent, 22 the issue, 2010.

[5] Chen, C. Prong. A probe into the cultivation of Design Professionals in Colleges and Universities for Creative Industries. Education and occupation, No. 30, 2011.

[6] Liu Yi ping, "Strategies for cultivating talents in Cultural and Creative Industries", in people's Forum, 35 the issue, 2010.

[7] Zhou Bin, A probe into the cultivation of Art and Design talents in the background of Creative Industry Development, Education Exploration, No. 12, 2010. 
[8] Zhao S m: research on the Strategy of Creative Talent cultivation, Journal of Nanjing University (philosophy, Humanities and Social Sciences), 2006, No. 6.

[9] Wang X h. The Application of Workshop Model in College Teaching. In Contemporary Education Forum, No. 8, 2011.

[10] Liu Yu, Wang Lai - Fu: A Study on the Practical Teaching System of Higher Education Based on Workshop, Journal of Northeastern University of Finance and Economics, No. 